\title{
Comparison of special judo fitness test and dynamic and isometric judo chin-up tests' performance and classificatory tables' development for cadet and junior athletes
}

\author{
Marcus Fábio Agostinho ${ }^{1,2}$, José Alfredo Olivio Junior ${ }^{2,3}$, Nemanja Stankovic ${ }^{4}$, Raquel Escobar-Molina ${ }^{5}$, Emerson Franchini ${ }^{1,6, *}$ \\ 'Martial Arts and Combat Sports Research Group, School of Physical Education and Sport, University of São Paulo, São Paulo, Brazil \\ Brazilian Judo Confederation, Rio de Janeiro, Brazil \\ ${ }^{3}$ São Paulo State University "Julio de Mesquita Filho" (UNESP), São Paulo, Brazil \\ ${ }^{4}$ Faculty of Sport and Physical Education, University of Nis, Nis, Serbia \\ ${ }^{5}$ Department of Physical Education and Sports, University of Granada, Granada, Spain \\ ${ }^{6}$ Combat Centre, Australian Institute of Sport, Canberra, Australia
}

The aims of this work were to compare the performances of male and female cadet and junior judo athletes and to develop classificatory tables to these judo-specific tests for international-level from these ages. Data collected during training camps of male and female cadet and junior judo teams from three nations (Brazil, Serbia, and Spain) were analyzed, totalizing 252 individual results of special judo fitness test (SJFT), and 222 and 208 of dynamic and isometric judogi chin-up tests, respectively. Juniors performed better than cadets in the SJFT, with higher number of throws in $A, B, C$, and total $(P<0.001$ for all comparisons), lower final heart rate $(P=0.021)$, and lower index $(P<0.001)$, as well as higher relative performance in the dynamic chin-up test $(P<0.001)$. Furthermore, male athletes presented better performance compared to female athletes in the SJFT (higher number of throws in A, B and total, and lower index) and in the isometric and dynamic chin-up tests (higher absolute and relative performances) $(P<0.001$ for all comparisons). Considering these differences, tables were established by sex and age groups, using percentile values. Thereby, each of the parameters of the SJFT (number of throws, heart rate after and 1 min after the test, and SJFT index), as well as absolute and relative results in chin-up judogi tests, were classified by sex and age. These classificatory tables can be useful for judo coaches to monitor specific physical performance during different phases of periodization process.

Keywords: Field tests, Combat sports, Sports performance, Young athletes

\section{INTRODUCTION}

Judo is a physiologically demanding combat sport that has as main goal to score an ippon, which can be achieved via throwing, immobilization, strangle, or elbow-lock techniques (International Judo Federation, 2017). During the match, most of the time $(\sim 50 \%)$ is spent in grip dispute (Miarka et al., 2012), which results in high levels of fatigue in the forearms and a need to developed strength-endurance to grip the opponent's judogi (judo uni-

form) (Franchini et al., 2013). When the athlete has grip control, it is possible to execute a throwing technique to try to score or to have the opportunity to continue the action on the ground (Franchini et al., 2013). To make the disputes more balanced, judo athletes are divided into weight and age categories, and nowadays World Championships are disputed for athletes in the under 18 years of age (cadets), under 21 years of age (juniors), above 21 years of age (seniors, although younger athletes can also compete), and above 30 years of age (masters, with age divisions for each

${ }^{*}$ Corresponding author: Emerson Franchini (D) https://orcid.org/0000-0002-0769-8398 School of Physical Education and Sport, University of São Paulo (USP), Av. Prof. Mello Morais, 65, Butantã, São Paulo, SP 05508-030, Brazil

Tel: +55-11-3091-2124, Fax: +55-11-3091-3135

E-mail: emersonfranchini@hotmail.com

Received: January 12, 2018 / Accepted: February 3, 2018 
5-year range) (International Judo Federation, 2017).

As the judo match has a duration of 4-min for these age groups and during this period athletes have sequences of 20-30s of actions and 5-10s of pauses (Miarka et al., 2012; Miarka et al., 2014), the match is predominantly aerobic, although the scoring actions are supported by the phosphagen and glycolytic energy systems (Julio et al., 2017). Thus, judo athletes must develop muscle power, maximal strength, strength-endurance and endurance to be successful in high-level competitions, and many training means and methods are applied to achieve a well-developed physical conditioning (Franchini et al., 2014).

During the training process, the monitoring of athletes' physical condition evolution is critical to improve training organization and different judo-specific tests have been developed to this end (Almansba et al., 2007; Azevedo et al., 2007; De Azevedo et al., 2014; Franchini et al., 2011b; Lidor et al., 2006; Santos et al., 2010; Sterkowicz, 1995). Among these tests, the special judo fitness test (SJFT) proposed by Sterkowicz (1995) has been reported as the most used test to evaluate judo athletes, can properly discriminate elite from nonelite judo athletes (Franchini et al., 2005), evaluate both anaerobic and aerobic components (Franchini et al., 2011c) and classificatory tables have been elaborated for both male (Franchini et al., 2009) and female judo athletes (Sterkowicz-Przybycień and Fukuda, 2014), allowing coaches to classify their athletes accordingly. Recently, two chin-up tests have also gained classificatory tables (Branco et al., 2017), because it was demonstrated that gripping is the longest action performed during the match (Marcon et al., 2010; Miarka et al., 2012; Miarka et al., 2014), involves strength-endurance and can properly discriminate judo athletes from different competitive level (Franchini et al., 2011b). Thus, considering that World Championships and World Rankings have been established for cadet and junior judo athletes and that the previous tables were not constituted by international-level only judo athletes for these age groups, the goal of the present study was to compare the performances of male and female cadet and junior judo athletes and to develop classificatory tables to the SJFT and to the dynamic and isometric judo chin-up tests for these groups.

\section{MATERIALS AND METHODS}

\section{Design}

This was a descriptive and comparative study conducted with cadet and junior judo national team members from Brazil, Serbia, and Spain. Athletes were submitted to the SJFT and dynamic and isometric judogi chin-up tests during training camps in preparation to international competitions. Thus, all athletes were tested in their competitive phase, after $24 \mathrm{hr}$ of rest and before the beginning of any weight loss procedure. The chin-up tests were conducted with 15-min intervals between them and after a 30-min rest, the SJFT was conducted.

\section{Sample}

Two hundred and sixty-six judo athletes from Brazil, Serbia, and Spain were evaluated. Athletes' age and body mass were as following (mean \pm standard deviation): female cadets $-60.4 \pm 14.7 \mathrm{~kg}$, $16.4 \pm 1.0$ years; male cadets $-70.7 \pm 22.1 \mathrm{~kg}, 16.4 \pm 1.0$ years; female juniors $-69.2 \pm 24.4 \mathrm{~kg}, 19.5 \pm 0.5$ years; male juniors $-86.9 \pm$ $26.1 \mathrm{~kg}, 19.7 \pm 0.5$ years. Not all athletes performed the three tests due to small injuries that avoid their normal execution, but the following number of athletes conducted each test:

(a) SJFT - 64 female cadets (52 from Brazil and 12 from Spain), 93 male cadets ( 77 from Brazil and 16 from Serbia), 50 female juniors (36 from Brazil and 14 from Spain), and 45 male juniors (24 from Brazil, 13 from Spain and 8 from Serbia);

(b) Dynamic judogi chin-up test - 60 female cadets (all from Brazil), 80 male cadets (65 from Brazil and 15 from Serbia); 35 female juniors (all from Brazil); 47 male juniors ( 40 from Brazil and 7 from Serbia);

(c) Isometric judogi chin-up test -52 female cadets (all from Brazil), 83 male cadets (68 from Brazil and 15 from Serbia), 30 female juniors (all from Brazil), and 43 male juniors (36 from Brazil and 7 from Serbia).

All athletes and their parents gave their informed consent to take part in the evaluation process. All procedures were approved by the Brazilian-located University Research Ethics Committee (approval number: 160.235/2012).

\section{Tests and measurements}

\section{Body mass}

Body mass $(\mathrm{kg}$ ) was measured using a Filizola (São Paulo, Brazil) digital scale (with $0.1-\mathrm{kg}$ precision) in accordance with Hey$\operatorname{ward}(1997)$.

\section{Special judo fitness test}

The execution of the SJFT followed the original recommendations by Sterkowicz (1995). Briefly, the SJFT is divided into three active periods (A, $15 \mathrm{sec}$; B and C, $30 \mathrm{sec}$ ) with 10-sec intervals between them. During each period, the athlete being evaluated throws 2 partners (separated from each other by a distance of $6 \mathrm{~m}$ ) 
as many times as possible using the ippon-seoi-nage technique. All participants involved with the test execution should present similar height and body mass characteristics. Immediately after and 1 min after completion of the test, the athletes' heart rate was measured using a heart rate monitor (Polar Electro Oy, Kempele, Finland). Thereafter, the SJFT index was calculated as follows:

Index $=($ HR after + HR 1 min after $) /$ total number of throws.

The reliability of this test variables was reported via interclass correlation coefficient: total number of throws - between 0.73 (Franchini et al., 1999) and 0.88 (Iredale, 2003); index - between 0.84 (Iredale, 2003) and 0.89 (Franchini et al., 1999). Iredale (2003) also reported that the typical error was $2.58 \%$ for the total number of throws and $4.85 \%$ for the index.

\section{Dynamic judogi chin-up}

This test followed the original recommendations by Franchini et al. (2011b). Briefly, the athletes were asked to extend their elbows completely and then flex them until the chin was above the hands gripping the judogi and complete as many correct repetitions as possible. The test was interrupted as soon as athletes were no longer able to carry out the proposed execution completely and/or gave up voluntarily. Athletes were monitored to guarantee the same movement patterns in the concentric and eccentric phases of movement. They were required to keep the knees extended and not allowed to elevate the knees or bend the trunk to aid the movement during testing. Finally, to relativize the work done by the athletes during this test body mass was multiplied by repetitions. The reliability of this test was reported via interclass correlation coefficient (0.98), and the limits of agreement (LOA) was -0.3 rep (95\% confidence interval: -0.9 to 0.3 rep) (Da Silva et al., 2012).

\section{Isometric judogi chin-up}

This test also followed the original recommendations by Franchini et al. (2011b). Briefly, the athletes were asked to keep their elbows flexed with their chin above the hands gripping the judogi for as long as possible and holding time was registered using a chronometer. The test was interrupted as soon as athletes were unable to maintain the initial isometric position. They started the test by gripping the judogi with bent elbows. When the athletes extended their elbows as a sign of fatigue, the test was interrupted and the chronometer was stopped; values with tenths of second were registered. Athletes were required to keep their knees extended and not allowed to elevate the knees or flex the trunk to aid to continue the isometric action for longer time. To relativize athletes' performance during this test body mass was multiplied by time in seconds. The reliability of this test was reported via interclass correlation coefficient (0.97) and its LOA was $-2.3 \mathrm{sec}$ (95\% confidence interval: -3.3 to $-1.2 \mathrm{sec}$ ) (Da Silva et al., 2012).

\section{Statistics}

Data are presented as mean and standard deviation, and 95\% confidence intervals. As all three tests depend on body mass displacement, a two-way (age and sex) analysis of covariance (body mass as covariate) was used to compared the number of throws during each series, total number of throws, heart rate immediately and $1 \mathrm{~min}$ after the ending of the SJFT, as well as time of suspension and number of repetitions during the isometric and dynamic judogi chin-up tests, respectively. As the relative values for both judogi chin-up tests already took body mass into consideration, the performances in these tests were compared using a two-way (age and sex) analysis of variance. An unequal sample size Tukey test was used as post hoc when a significant difference was detected in the analysis of variance or analysis of covariance analyses. Pearson correlation coefficient was used to verify the relationship between variables from the three tests, and classified according to Hopkins (2006). Significance level was set at $5 \%$ for all tests. Partial eta squared $\left(\eta^{2}\right)$ was used as effect size, and classified as proposed by Cohen (1969). For the analyses the Statistica for Windows version 10 was used.

Considering that at least one difference was found between groups, except for heart rate $1 \mathrm{~min}$ after the SJFT, for each test scales percentile values were adopted to establish the following categories, as suggested by Sterkowicz-Przybycień and Fukuda (2014): excellent, highest 5\%; good, next 15\%; regular, middle $60 \%$; poor, next lowest $15 \%$; very poor, lowest $5 \%$.

\section{RESULTS}

Table 1 presents the SJFT performance for each group.

For the number of throws during series $\mathrm{A}$, effects of age $(F[1$, $247]=21.41, P<0.001$, partial $\eta^{2}=0.080$ [medium]), with higher values for juniors compared to cadets $(P=0.020)$, and sex ( $F[1$, 247] $=50.44, P<0.001$, partial $\eta^{2}=0.171$ [large]), with higher values for males compared to females $(P<0.001)$, were found.

For the number of throws during series $\mathrm{B}$, there were effects of age $\left(F[1,247]=43.13, P<0.001\right.$, partial $\eta^{2}=0.150$ [large] $)$, with higher values for juniors compared to cadets $(P=0.032)$, and sex $\left(F[1,247]=23.90, P<0.001\right.$, partial $\eta^{2}=0.089$ [medium] $)$, with higher values for males compared to females $(P<0.001)$. 
The number of throws during series $C$ differed between age groups $\left(F[1,247]=16.39, P<0.001\right.$, partial $\eta^{2}=0.063$ [medium] $)$, with higher values for juniors compared to cadets $(P<0.001)$.

For the total number of throws, effects of age $(F[1,247]=25.58$, $P<0.001$, partial $\eta^{2}=0.095$ [medium]), with higher values for juniors compared to cadets $(P=0.022)$, and $\operatorname{sex}(F[1,247]=54.38$, $P<0.001$, partial $\eta^{2}=0.182$ [large]), with higher values for males compared to females $(P<0.001)$, were observed.

Heart rate immediately after the SJFT differed between age groups $\left(F[1,247]=5.40, P=0.021\right.$, partial $\eta^{2}=0.021$ [small] $)$, with higher values for cadets compared to juniors $(P=0.022)$. No differences were revealed for heart rate $1 \mathrm{~min}$ after the SJFT $(P>$ 0.05).

The index of the SJFT differed between age $(F[1,247]=25.32$, $P<0.001$, partial $\eta^{2}=0.095$ [small]), with lower values for juniors compared to cadets $(P=0.032)$, and $\operatorname{sex}(F[1,247]=49.69, P<$ 0.001 , partial $\eta^{2}=0.172$ [large]), with lower values for males compared to females $(P<0.001)$. Additionally, an age and sex interaction was observed $\left(F[1,247]=3.92, P=0.049\right.$, partial $\eta^{2}=$ 0.016 [small]), with lower values for male juniors compared to both female groups ( $P<0.001$ for both comparisons) and to the male cadets $(P=0.014)$, and lower values for the male cadets com- pared to female cadets $(P=0.018)$.

Isometric and dynamic chin-up gripping the judogi tests performances are presented on Table 2 .

Concerning suspension time, there was an effect of sex $(F[1$, 213] $=81.82, P<0.001$, partial $\eta^{2}=0.287$ [large]), with higher values for males compared to females $(P<0.001)$. For the relative suspension time, there was a sex effect $(F[1,214]=115.75, P<$ 0.001 , partial $\eta^{2}=0.351$ [large]), with higher values for males compared to females $(P<0.001)$.

The number of repetitions differed between sex groups $(F[1$, 217] $=152.28, P<0.001$, partial $\eta^{2}=0.399$ [large] , with higher values for males compared to females $(P<0.001)$. For the relative number of repetitions, effects of age $(F[1,218]=6.24, P<0.001$, partial $\eta^{2}=0.013$ [medium]), with higher values for juniors compared to cadets $(P=0.022)$, and $\operatorname{sex}(F[1,218]=157.56, P<0.001$, partial $\eta^{2}=0.403$ [large]), with higher values for males compared to females $(P<0.001)$, were observed. Additionally, an age and sex interaction effect was detected $(F[1,217]=152.28, P<0.001$, partial $\eta^{2}=0.399$ [large]), with higher values for male juniors compared to the two female groups ( $P<0.001$ for both comparisons) and to the male cadet group $(P=0.007)$, and higher values for the male cadets compared to both female groups $(P<0.001$ for both

Table 1. Special judo fitness test performance in male and female cadet and junior judo athletes

\begin{tabular}{|c|c|c|c|c|}
\hline Variable & Female cadets $(n=64)$ & Male cadets $(n=93)$ & Female juniors $(n=50)$ & Male juniors ( $n=45$ ) \\
\hline Throws in series $A(\text { rep })^{a, b)}$ & $5.8 \pm 0.5(5.7-5.9)$ & $6.2 \pm 0.6(6.0-6.3)$ & $6.0 \pm 0.7(5.8-6.2)$ & $6.5 \pm 0.7(6.3-6.7)$ \\
\hline Throws in series $B(\text { rep })^{a, b)}$ & $10.1 \pm 1.0(9.9-10.4)$ & $10.6 \pm 0.9(10.4-10.8)$ & $10.4 \pm 1.1(10.1-10.7)$ & $11.0 \pm 1.1(10.6-11.3)$ \\
\hline Throws in series C $(\text { rep })^{\text {al }}$ & $9.0 \pm 1.0(8.8-9.3)$ & $9.5 \pm 1.0(9.3-9.7)$ & $9.2 \pm 1.3(8.9-9.6)$ & $10.0 \pm 1.1(9.6-10.3)$ \\
\hline Total throws (rep) ${ }^{\mathrm{a}, \mathrm{b})}$ & $24.9 \pm 2.3(24.4-25.5)$ & $26.2 \pm 2.2(25.8-26.7)$ & $25.6 \pm 2.7(24.8-26.4)$ & $27.4 \pm 2.7(26.6-28.2)$ \\
\hline HR immediately after (bpm) & $184 \pm 10(182-187)$ & $185 \pm 11$ (183-188) & $183 \pm 9(181-186)$ & $180 \pm 11(177-183)$ \\
\hline HR 1 min after (bpm) & $165 \pm 16(161-170)$ & $163 \pm 15(160-166)$ & $164 \pm 15(160-168)$ & $156 \pm 17(151-162)$ \\
\hline Index (bpm/throw) ${ }^{c, d)}$ & $14.19 \pm 1.95(13.69-14.69)$ & $13.36 \pm 1.41(13.07-13.66)^{e)}$ & $13.76 \pm 1.97(13.20-14.33)$ & $12.35 \pm 1.36(11.93-12.77)^{\dagger}$ \\
\hline
\end{tabular}

Values are presented as mean \pm standard deviation ( $95 \%$ confidence intervals). $H R$, heart rate.

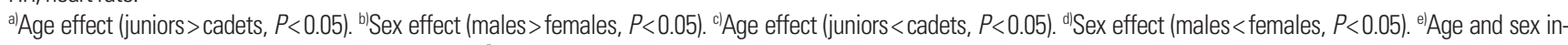
teraction effect (male cadet $<$ female cadet, $P<0.05$ ). ${ }^{\text {f)} A g e ~ a n d ~ s e x ~ i n t e r a c t i o n ~ e f f e c t ~(m a l e ~ j u n i o r ~}<$ all other groups, $P<0.05$ ).

Table 2. Absolute and relative isometric and dynamic chin-up gripping the judogi in male and female cadet and junior judo athletes

\begin{tabular}{lcccc}
\hline Variable & Female cadets $(n=62 / 60)$ & Male cadets $(n=83 / 80)$ & Female juniors $(n=30 / 35)$ & Male juniors $(n=43 / 47)$ \\
\hline Isometric chin-up (sec) & $41.6 \pm 16.7(36.9-46.2)$ & $54.9 \pm 20.8(50.3-59.4)$ & $41.3 \pm 22.9(32.7-49.9)$ & $49.9 \pm 18.7(44.1-55.6)$ \\
Dynamic chin-up (rep) & $11 \pm 7(9-13)$ & $20 \pm 8(18-21)$ & $12 \pm 9(9-15)$ & $21 \pm 9(19-24)$ \\
Isometric chin-up (sec.kg) & $1,914 \pm 1,224(1,592-2,236)$ & $3,628 \pm 1,327(3,338-3,918)$ & $1,627 \pm 1,381(1,145-2,109)$ & $3,919 \pm 1,285(3,524-4,315)$ \\
Dynamic chin-up (rep.kg) & $569 \pm 402(467-671)$ & $1,315 \pm 569(1,197-1,432)^{(a)}$ & $582 \pm 486(418-747)$ & $1,665 \pm 615(1,485-1,846)^{d)}$ \\
\hline
\end{tabular}

Values are presented as mean \pm standard deviation ( $95 \%$ confidence intervals). Numbers represents number of athletes who performed the isometric and dynamic tests, respectively.

${ }^{a l}$ Sex effect (males $>$ females, $P<0.05$ ). ${ }^{\text {bl}}$ Age effect (juniors $>$ cadets, $P<0.05$ ). ${ }^{c / I}$ nteraction effect (male cadet $>$ both female groups, $\left.P<0.001\right)$. dIInteraction effect (male junior $>$ all other groups, $P<0.01)$. 
comparisons).

Tables 3 to 6 present the SJFT classificatory data for female cadets, female juniors, male cadets and male juniors, respectively.

Tables 7 to 10 present the isometric and dynamic chin-up grip-

Table 3. Special judo fitness test classificatory table for high-level female cadet judo athletes

\begin{tabular}{lcccc}
\hline Level & No. of throws & $\begin{array}{c}\text { HR after } \\
\text { (beats/min) }\end{array}$ & $\begin{array}{c}\text { HR 1 min after } \\
\text { (beats/min) }\end{array}$ & Index \\
\hline Excellent & $\geq 28$ & $\leq 168$ & $\leq 132$ & $\leq 11.53$ \\
Good & 27 & $169-176$ & $133-148$ & $11.54-12.63$ \\
Regular & $23-26$ & $177-193$ & $149-176$ & $12.64-15.45$ \\
Poor & $21-22$ & $194-202$ & $177-189$ & $15.46-18.00$ \\
Very poor & $\leq 20$ & $\geq 203$ & $\geq 190$ & $\geq 18.01$ \\
\hline
\end{tabular}

$H R$, heart rate.

Table 4. Special judo fitness test classificatory table for high-level female junior judo athletes

\begin{tabular}{lcccc}
\hline Level & No. of throws & $\begin{array}{c}\text { HR after } \\
\text { (beats/min) }\end{array}$ & $\begin{array}{c}\text { HR 1 min after } \\
\text { (beats/min) }\end{array}$ & Index \\
\hline Excellent & $\geq 30$ & $\leq 168$ & $\leq 148$ & $\leq 11.48$ \\
Good & $28-29$ & $169-179$ & $149-157$ & $11.49-12.00$ \\
Regular & $25-27$ & $180-190$ & $158-176$ & $12.01-14.70$ \\
Poor & $22-24$ & $191-196$ & $177-180$ & $14.71-17.45$ \\
Very poor & $\leq 21$ & $\geq 197$ & $\geq 181$ & $\geq 17.46$ \\
\hline
\end{tabular}

$H R$, heart rate.

Table 5. Special Judo Fitness Test classificatory table for high-level male cadet judo athletes

\begin{tabular}{lcccc}
\hline Level & No. of throws & $\begin{array}{c}\text { HR after } \\
\text { (beats/min) }\end{array}$ & $\begin{array}{c}\text { HR 1 min after } \\
\text { (beats/min) }\end{array}$ & Index \\
\hline Excellent & $\geq 30$ & $\leq 163$ & $\leq 132$ & $\leq 11.15$ \\
Good & $28-29$ & $164-174$ & $133-148$ & $11.16-12.38$ \\
Regular & $25-27$ & $175-195$ & $149-175$ & $12.39-14.32$ \\
Poor & $23-24$ & $196-200$ & $176-184$ & $14.33-15.92$ \\
Very poor & $\leq 22$ & $\geq 201$ & $\geq 185$ & $\geq 15.93$ \\
\hline
\end{tabular}

$H R$, heart rate.

Table 6. Special judo fitness test classificatory table for high-level male junior judo athletes

\begin{tabular}{lcccc}
\hline Level & No. of throws & $\begin{array}{c}\text { HR after } \\
\text { (beats/min) }\end{array}$ & $\begin{array}{c}\text { HR 1 min after } \\
\text { (beats/min) }\end{array}$ & Index \\
\hline Excellent & $\geq 31$ & $\leq 162$ & $\leq 127$ & $\leq 10.40$ \\
Good & 30 & $163-174$ & $128-144$ & $10.41-11.29$ \\
Regular & $26-29$ & $175-188$ & $145-168$ & $11.30-13.52$ \\
Poor & $23-25$ & $189-198$ & $169-184$ & $13.53-14.18$ \\
Very poor & $\leq 22$ & $\geq 199$ & $\geq 185$ & $\geq 14.19$ \\
\hline
\end{tabular}

$H R$, heart rate. ping the judogi classificatory data for female cadets, female juniors, male cadets and male juniors, respectively.

When the whole group was considered, body mass was negatively correlated to number of throws (from $r=-0.15$ to -0.24 , $P<0.001$, small $)$ and positively correlated to the index $(r=0.19$, $P=0.003$, small) during the SJFT, and negatively correlated $(P<$ $0.001)$ to the suspension time $(r=-0.52$, large) and number of

Table 7. Absolute and relative isometric and dynamic chin-up gripping the judogi classificatory table for high-level female cadet judo athletes

\begin{tabular}{lcccc}
\hline Level & $\begin{array}{c}\text { Isometric } \\
\text { chin-up (sec) }\end{array}$ & $\begin{array}{c}\text { Dynamic } \\
\text { chin-up (rep) }\end{array}$ & $\begin{array}{c}\text { Isometric chin-up } \\
\text { (sec.kg) }\end{array}$ & $\begin{array}{c}\text { Dynamic chin-up } \\
\text { (rep.kg) }\end{array}$ \\
\hline Excellent & $\geq 75$ & $\geq 23$ & $\geq 3,406$ & $\geq 1,143$ \\
Good & $56-74$ & $17-22$ & $2,933-3,405$ & $800-1,142$ \\
Regular & $27-55$ & $6-16$ & $1,515-2,932$ & $351-799$ \\
Poor & $13-26$ & $2-5$ & $555-1,514$ & $145-350$ \\
Very poor & $\leq 12$ & $\leq 1$ & $\leq 554$ & $\leq 144$
\end{tabular}

Table 8. Absolute and relative isometric and dynamic chin-up gripping the judogi classificatory table for high-level female junior judo athletes

\begin{tabular}{lcccc} 
Level & $\begin{array}{c}\text { Isometric } \\
\text { chin-up (sec) }\end{array}$ & $\begin{array}{c}\text { Dynamic } \\
\text { chin-up (rep) }\end{array}$ & $\begin{array}{c}\text { Isometric chin-up } \\
\text { (sec.kg) }\end{array}$ & $\begin{array}{c}\text { Dynamic chin-up } \\
\text { (rep.kg) }\end{array}$ \\
\hline Excellent & $\geq 72$ & $\geq 24$ & $\geq 3,934$ & $\geq 1,297$ \\
Good & $58-71$ & $21-23$ & $3,217-3,933$ & $1,057-1,296$ \\
Regular & $18-57$ & $4-20$ & $1,233-3,216$ & $307-1,056$ \\
Poor & $3-17$ & $1-3$ & $244-1,232$ & $59-306$ \\
Very poor & $\leq 2$ & 0 & $\leq 243$ & $\leq 58$ \\
\hline
\end{tabular}

Table 9. Absolute and relative isometric and dynamic chin-up gripping the judogi classificatory table for high-level male cadet judo athletes

\begin{tabular}{lcccc} 
Level & $\begin{array}{c}\text { Isometric } \\
\text { chin-up (sec) }\end{array}$ & $\begin{array}{c}\text { Dynamic } \\
\text { chin-up (rep) }\end{array}$ & $\begin{array}{c}\text { Isometric chin-up } \\
\text { (sec.kg) }\end{array}$ & $\begin{array}{c}\text { Dynamic chin-up } \\
\text { (rep.kg) }\end{array}$ \\
\hline Excellent & $\geq 90$ & $\geq 32$ & $\geq 5,857$ & $\geq 2,245$ \\
Good & $70-89$ & $26-31$ & $4,507-5,856$ & $1,738-2,244$ \\
Regular & $41-69$ & $14-25$ & $2,745-4,506$ & $785-1,737$ \\
Poor & $8-40$ & $3-13$ & $627-2,744$ & $227-784$ \\
Very poor & $\leq 7$ & $\leq 2$ & $\leq 626$ & $\leq 226$ \\
\hline
\end{tabular}

Table 10. Absolute and relative isometric and dynamic chin-up gripping the judogi classificatory table for high-level male junior judo athletes

\begin{tabular}{lcccc}
\hline Level & $\begin{array}{c}\text { Isometric } \\
\text { chin-up (sec) }\end{array}$ & $\begin{array}{c}\text { Dynamic } \\
\text { chin-up (rep) }\end{array}$ & $\begin{array}{c}\text { Isometric chin-up } \\
\text { (sec.kg) }\end{array}$ & $\begin{array}{c}\text { Dynamic chin-up } \\
\text { (rep.kg) }\end{array}$ \\
\hline Excellent & $\geq 76$ & $\geq 31$ & $\geq 5,714$ & $\geq 2,367$ \\
Good & $66-75$ & $29-30$ & $4,733-5,713$ & $2,027-2,366$ \\
Regular & $35-65$ & $16-28$ & $3,159-4,732$ & $1,159-2,026$ \\
Poor & $7-34$ & $4-15$ & $823-3,158$ & $412-1,158$ \\
Very poor & $\leq 6$ & $\leq 3$ & $\leq 822$ & $\leq 411$ \\
\hline
\end{tabular}


repetitions ( $r=-0.30$, moderate) in the chin-up tests. Number of throws in the SJFT was positively correlated to suspension time (absolute, $r=0.43$; relative, $r=0.39$, moderate, $P<0.001$ for both correlations), and to number of repetitions (absolute, $r=0.56$; relative, $r=0.53$, large, $P<0.001$ for both correlations). The SJFT Index was negatively correlated to suspension time (absolute, $r=$ -0.46; relative, $r=-0.41$, moderate, $P<0.001$ for both correlations), and to number of repetitions (absolute, $r=-0.60$; relative, $r=-0.56$, large, $P<0.001$ for both correlations). Absolute performance in the isometric chin-up test was positively correlated to that in the dynamic test $(r=0.80$, very large, $P<0.001)$, and the same was observed for relative values $(r=0.85$, very large, $P<0.001)$.

\section{DISCUSSION}

The main findings of the present study were: (a) juniors performed better in the SJFT (higher number of throws in A, B, C, and total, and lower final heart rate and index) and had higher relative performance in the dynamic chin-up test compared to cadets; (b) male athletes performed better in the SJFT (higher number of throws in A, B, and total, and lower index) and presented higher absolute and relative performances in the isometric and dynamic chin-up tests compared to females; (c) male juniors had a lower index in the SJFT (i.e., better performance) and higher relative performance in the dynamic chin-up test compared to both female groups and the male cadets, while the performance for the male cadets was higher than that for the female cadets in these variables; (d) body mass was negatively related to all performance variables where body mass displacement was needed (i.e., number of throws during the different series of the SJFT and absolute performance in the chin-up tests; although small magnitude of the correlations was found). Moreover, performance in the different tests was moderate to very large related between them, suggesting that the best athletes perform better in all these tests. Additionally, eight classificatory tables were created, considering each of the three tests, the two age and the two sex groups.

Concerning the differences in performance between age groups in the chin-up tests, and considering that these tests are related to isometric handgrip performance (Franchini et al., 2004), lower values have been reported for cadet compared to junior judo athletes in maximal isometric handgrip strength (Little, 1991). As the total number of throws have been reported to be positively associated to Wingate test performance (Sterkowicz-Przybycień et al., 2017), the differences observed between cadet and junior judo athletes during this test can be used to explain the differences be- tween age groups found in our study. In fact, cadets also presented lower mean and peak power during Wingate test compared to junior judo athletes (Little, 1991). Studies with grappling combat sports athletes (Little, 1991; Terbizan and Seljevold, 1996) and with non-athletes (Blimkie et al., 1988; Falk and Bar-Or, 1993; Inbar and Bar-Or, 1986; Nindl et al., 1995) suggested that differences in anaerobic capacity and maximal isometric strength between adolescents and adults are probably related to maturational aspects, such as higher testosterone release, increased muscle mass and glycolytic activity for the more matured athletes. One limitation of our study is that sexual maturation was not assessed, which does not allow us to infer if this was the cause of the difference between our groups. Nevertheless, as the difference was independent of sex, it is important to consider that this maturational effect is unlikely to have influenced the difference in the female groups, as athletes in the age of the cadet female group are normally sexually mature (Malina et al., 2004). Furthermore, the relative suspension time of the male cadets was longer than that observed in the female cadets, which makes unlikely that the maturational status is the main contributor factor for the differences between age groups. Although no study compared the performance in the SJFT between cadet and junior judo athletes, a recent meta-analysis indicated that seniors performed better than junior judo athletes in this test (Sterkowicz-Przybycień et al., 2017). As junior and senior judo athletes are probably sexually mature, the longer time of judo training seems to be a plausible explanation for these differences.

Regarding the sex differences, similar findings have been reported in nonspecific tests. Specifically, higher values of maximal absolute isometric handgrip strength were reported in male than in female Brazilian (Franchini et al., 1997) and Canadian judo athletes (Little, 1991), which may explain the lower performance of females in the isometric chin-up test. Additionally, maximal dynamic strength was reported to be higher in male than in female counterparts of the Italian Olympic Judo Team (Sbriccoli et al., 2007), and a study conducted with the Japanese Olympic Team (Ichinose et al., 1998) indicated that females' isokinetic maximal elbow extension was $92 \%$ of that achieved by males at low speed $(60 \% \mathrm{sec})$ and $88 \%$ of the values achieved at $180^{\circ} / \mathrm{sec}$, which may explain the difference between sexes we observed in the dynamic chin-up test. The lower female performance in the SJFT in relation to males' results is probably related to the lower anaerobic power and capacity for females, as lower Wingate test mean and peak power was also observed in female compared to male judo athletes (Franchini et al., 2011a). These differences in 
strength-endurance and in anaerobic capacity are attributed to the lower testosterone release, muscle mass and glycolytic activity in females compared to males (McArdle et al., 2013). Additionally, as the SJFT has a significant oxidative contribution (Franchini et al., 2011c), the higher maximal oxygen consumption observed in male than in female judo athletes is probably an important aspect contributing to the higher performance of males in the SJFT. The combination of the above factors used to explain age and sex differences can also explain the better SJFT index and relative suspension time observed in male junior judo athletes compared to all other groups.

For the SJFT, previous investigations have already presented the performance of males from cadet to master age categories (Franchini et al., 2009) and for junior and senior female athletes (Sterkowicz-Przybycień and Fukuda, 2014). Despite the different approaches used in these two studies to create the classificatory tables, the results from our high-level cadet and junior judo athletes are quite similar to judo athletes from different competitive levels reported in these previous classificatory tables.

For the chin-up tests, only one classificatory table is available (Branco et al., 2017). The absolute results from our sample and that from Branco et al. (2017) differ basically in the more extreme classifications, with our athletes presenting a higher performance in the excellent zone and a lower performance in the very poor one. Concerning the relative values, again a higher heterogeneity was observed in our groups, as to be classified as excellent a much higher value should be achieved and to be classified as very poor a much worse performance would be needed. This higher heterogeneity in our groups is probably due to different level of competitiveness normally observed in young athletes, especially when considering the different weight categories and the typical body mass distribution in the population (i.e., lower number of athletes competing in the lighter and heavier categories compared to athletes in the middleweight categories).

Finally, the correlations observed between body mass and judo-specific tests performances results partially confirm the suggestion by Kuvaćić et al. (2017) that factors of success in judo differ depending on the body mass. The correlations found between the different tests used in the present study indicate that the best judo athletes have a well-developed anaerobic capacity and strength-endurance. Additionally, as the chin-up tests performance were highly correlated, only one of these tests can be used, especially when there are time restrictions to conduct the physical evaluation of judo athletes.

In conclusion, juniors performed better than cadets, and males performed better than females in the SJFT and isometric and dynamic chin-up gripping the judogi tests. Additionally, the normative data were established based on high-level cadet and junior judo athletes from Brazil, Serbia, and Spain, and the results of any high-level athlete from these ages can now be evaluated by using a 5-grade scale proposed here, and used as a reference to guide young athletes' evaluation, training, and during the rehabilitation processes. Thus, coaches, strength and conditioning professionals, and physiotherapists now have a detailed sex and age specific classification for judo-specific aerobic and anaerobic fitness, as well as judo-specific strength-endurance performance. The use of these tests and classifications can be relevant for goal setting in terms of physical development either aiming at peaking for a specific competition or during different phases of the rehabilitation process. The responses to different types of periodization can also be monitored through the application of these tests.

\section{CONFLICT OF INTEREST}

No potential conflict of interest relevant to this article was reported.

\section{ACKNOWLEDGMENTS}

The authors thank the Brazilian Judo Confederation, Serbian and Spanish Judo Federations. Additionally, we also thank the Brazilian national coaches Douglas Vieira, Danusa Bittencourt, Andrea Berti, Alexandre Katsuragi and Douglas Potrich, and Brazilian managers Matheus Theotonio, Edmilson Guimarães and Marcelo Theotonio for their contributions in the data collection. The authors thank the Brazilian Sports Ministry and the CNPq for the partial financial support to conduct this study (process number: 487302/2013-3). The last author is supported by a FAPESP grant: 2017/08167-2.

\section{REFERENCES}

Almansba R, Franchini E, Sterkowicz S. Uchi-komi avec charge, une approche physiologique d'um nouveau test spécifique au judo. Sci Sports 2007;22:216-223.

Azevedo PH, Drigo AJ, Carvalho MC, Oliveira JC, Nunes JE, Baldissera V, Perez SE. Determination of judo endurance performance using the uchi-komi technique and an adapted lactate minimum test. J Sports Sci Med 2007;6(CSSI-2):10-14.

Blimkie CJ, Roache P, Hay JT, Bar-Or O. Anaerobic power of arms in teen- 
age boys and girls: relationship to lean tissue. Eur J Appl Physiol Occup Physiol 1988;57:677-683.

Branco BH, Diniz E, Santos JF, Shiroma AS, Franchini E. Normative tables for the dynamic and isometric judogi chin-up tests for judo athletes. Sport Sci Health 2017;13:47-53.

Cohen J. Statistical power analysis for the behavioural sciences. New York: Academic Press; 1969.

Da Silva BV, Marocolo M Jr, de Moura Simim MA, Rezende FN, Franchini E, Mota GR. Reliability in kimono grip strength tests and comparison between elite and non-elite brazilian jiu-jitsu players. Arch Budo 2012;8:103-107.

De Azevedo PH, Pithon-Curi T, Zagatto AM, Oliveira J, Perez S. Maximal lactate steady state in Judo. Muscles Ligaments Tendons J 2014;4:132136.

Falk B, Bar-Or O. Longitudinal changes in peak aerobic and anaerobic mechanical power of circumpubertal boys. Pediatric Exerc Sci 1993;5: 318-331.

Franchini E, Artioli GG, Brito CJ. Judo combat: time-motion analysis and physiology. Int J Perform Anal Sport 2013;13:624-641.

Franchini E, Brito CJ, Fukuda DH, Artioli GG. The physiology of judospecific training modalities. J Strength Cond Res 2014;28:1474-1481.

Franchini E, Del Vecchio FB, Matsushigue KA, Artioli GG. Physiological profiles of elite judo athletes. Sports Med 2011a;41:147-166.

Franchini E, Del Vecchio FB, Sterkowicz S. A Special judo fitness test classificatory table. Arch Budo 2009;5:127-129.

Franchini E, Miarka B, Matheus L, Del Vecchio FB. Endurance in judogi grip strength test: comparison between elite and non-elite judo players. Arch Budo 2011b;7:1-4.

Franchini E, Nakamura FY, Takito MY, Kiss MA, Sterkowicz S. Análise de um teste especifico para o judô. Kinesis 1999;21:91-108.

Franchini E, Souza CE, Urasaki R, Oliveira RS, Sauressig F, Matheus L. Teste de resistência de força isométrica e dinâmica na barra com o judogi. In: Proceedings of III Congreso De La Asociación Española De Ciencia Del Deporte, 2004, Madrid, España.

Franchini E, Sterkowicz S, Szmatlan-Gabrys U, Gabrys T, Garnys M. Energy system contributions to the special judo fitness test. Int J Sports Physiol Perform 2011c;6:334-343.

Franchini E, Takito MY, Kiss M, Sterkowicz S. Physical fitness and anthropometrical differences between elite and non-elite judo players. Biol Sport 2005;22:315-328.

Franchini E, Takito MY, Matheus L, Vieira, DE, Kiss, MA. Composição corporal, somatotipo e força isométrica em atletas da seleção brasileira universitária de judô. Âmbito Med Desp 1997;34:21-29.

Heyward VH. Advanced fitness assessment \& exercise prescription. 3rd ed. Champaign (IL): Human Kinetics; 1997.
Hopkins WG. A new view of statistics: a scale of magnitudes for effect statistics [Internet]. Internet Society of Sports Science. 2006 [updated 2006 Aug 7; cited 2018 Jan 2]. Available from: http://www.sportsci.org/ resource/stats/effectmag.html.

Ichinose Y, Kanehisa H, Ito M, Kawakami Y, Fukunaga T. Morphological and functional differences in the elbow extensor muscle between highly trained male and female athletes. Eur J Appl Physiol Occup Physiol 1998;78:109-114.

Inbar O, Bar-Or O. Anaerobic characteristics in male children and adolescents. Med Sci Sports Exerc 1986;18:264-269.

International Judo Federation (IJF). Sports and organization rules of the international judo federation [Internet]. Lausanne (Switzerland): International Judo Federation; 2017 [cited 2017 Oct 14], Available from: http://99e89a50309ad79ff91d-082b8fd5551e97bc65e327988b444396.r14. cf3.rackcdn.com/up/2017/03/2017_IJF_SOR_version_19-03-201-149078 8080.pdf.

Iredale F. Determining reliability in a judo specific fitness test. Proceedings of the 3rd IJF Conference; Osaka (Japan). 2003.

Julio UF, Panissa VLG, Esteves JV, Cury RL, Agostinho MF, Franchini E. Energy-system contributions to simulated judo matches. Int J Sports Physiol Perform 2017;12:676-683.

Kuvačić G, Krstulović S, Caput PĐ. Factors determining success in youth judokas. J Hum Kinet 2017;56:207-217.

Lidor R, Melnik Y, Bilkevitz A, Falk B. The ten-station judo ability test: a test of physical and skill components. Strength Cond J 2006;28:18-20.

Little NG. Physical performance attributes of junior and senior women, juvenile, junior, and senior men judokas. J Sports Med Phys Fitness 1991;31:510-520.

Malina RM, Bouchard C, Bar-Or O. Growth, maturation, and physical activity. 2nd ed. Champaign (IL): Human Kinetics Publishers; 2004.

Marcon G, Franchini E, Jardim JR, Barros Neto TL. Structural analysis of action and time in sports: judo. J Quant Anal Sports 2010;6:1-13.

McArdle WD, Katch FL, Katch VL. Exercise physiology: nutrition, energy and human performance. Philadelphia (PA): Lippincott Williams \& Wilkins; 2013.

Miarka B, Cury R, Julianetti R, Battazza R, Julio UF, Calmet M, Franchini E. A comparison of time-motion and technical-tactical variables between age groups of female judo matches. J Sports Sci 2014;32:15291538 .

Miarka B, Panissa VL, Julio UF, Del Vecchio FB, Calmet M, Franchini E. A comparison of time-motion performance between age groups in judo matches. J Sports Sci 2012;30:899-905.

Nindl BC, Mahar MT, Harman EA, Patton JF. Lower and upper body anaerobic performance in male and female adolescent athletes. Med Sci Sports Exerc 1995;27:235-241. 
Santos L, González V, Iscar M, Brime JI, Fernandez-Rio J, Egocheaga J, Rodríguez B, Montoliu MA. A new individual and specific test to determine the aerobic-anaerobic transition zone (Santos Test) in competitive judokas. J Strength Cond Res 2010;24:2419-2428.

Sbriccoli P, Bazzucchi I, Di Mario A, Marzattinocci G, Felici F. Assessment of maximal cardiorespiratory performance and muscle power in the Italian Olympic judoka. J Strength Cond Res 2007;21:738-744.

Sterkowicz S. Test specjalnej sprawnoci ruchowej w judo. Antropomotoryka 1995;12:29-44.
Sterkowicz-Przybycień K, Fukuda DH, Franchini E, Sterkowicz S. Special judo fitness test: results and applications. Drid P, editor. Science and medicine in combat sports. New York: Nova Publishers; 2017. p. 145173.

Sterkowicz-Przybycień KL, Fukuda DH. Establishing normative data for the special judo fitness test in female athletes using systematic review and meta-analysis. J Strength Cond Res 2014;28:3585-3593.

Terbizan DJ, Seljevold PJ. Physiological profile of age-group wrestlers. J Sports Med Phys Fitness 1996;36:178-185. 